\title{
ARTículo
}

\section{Geomorfología de litorales - Caso: Humedales de Ventanilla - Provincia Constitucional del Callao - Lima}

\section{Coastal geomorphology - Case: Ventanilla Wetlands - Constitutional Province of Callao - Lima}

\author{
Juan Felipe Meléndez de la Cruz \\ Universidad Nacional Mayor de San Marcos \\ melendezd@unmsm.edu.pe
}

\section{RESUMEN}

Desde el punto de vista geomorfológico, el Área de Conservación Regional de los Humedales de Ventanilla corresponde a zonas de acantilados y marismas. Se ha seleccionado como área de estudio el sector de acantilados y marismas, de la mencionada área de conservación, porque se encuentran poco alteradas por la población. El estudio trata de un análisis geomorfológico basado en las formas del relieve, litología, procesos geodinámicos y morfogénesis. El trabajo está acompañado de un mapa geomorfológico.

Palabras Clave: Geomorfología; geoformas; litología; morfogénesis y geodinámica.

\section{ABSTRACT}

From the geomorphological point of view the Regional Conservation Area of the Ventanilla Wetlands corresponds to areas of cliffs and marshes. The sector of cliffs and marshes, of the aforementioned conservation area, which has been little altered by the population, has been selected as study area. The study deals with a geomorphological analysis based on relief forms, lithology, geodynamic processes and morphogenesis. The work is accompanied by a geomorphological map.

Keywords: Geomorphology; geoforms; lithology; morphogenesis and geodynamics. 


\section{INTRODUCCIÓN}

En el plano geomorfológico, los Humedales de Ventanilla se encuentran en una zona de marismas y acantilados. Es un espacio típico de litorales con terrenos en general a cero metros sobre el nivel del mar, incluso debajo de ese nivel debido a depresiones causadas por la deflación (erosión eólica al impactar verticalmente, a gran velocidad, el viento cargado de partículas sobre el terreno arenoso). Se trata de espacios continentales que se encuentran en contacto con el mar mediante intrusiones marinas, mareas, oleajes y excepcionalmente tsunamis. Las geoformas de mayor notoriedad son los siguientes: acantilados, cavernas (conocidos popularmente como ventanas), cordón litoral, planicie arenosa y albuferas.

\section{Planteamiento del problema}

Son pocas las áreas de litoral que se encuentran poco alteradas en Lima Metropolitana. El área de estudio es una muestra relevante de la mencionada zona de marismas y de los acantilados porque se encuentra poco modificadas por el proceso de urbanización. Asimismo, es un espacio que forma parte del Área de Conservación Regional Humedales de Ventanilla.

\section{Justificación}

Por un lado, se ha estudiado mucho las bondades ecológicas del área de estudio, sin embargo, hace falta investigar más sobre la geomorfología del lugar. Teniendo en cuenta la relación entre las geoformas y los ecosistemas que alberga, se puede tener una visión más precisa de la ecología del área de trabajo.

\section{Objetivo general}

El objetivo del presente trabajo es llevar a cabo un análisis geomorfológico mediante un levantamiento de las geoformas a escala grande, señalando los procesos geodinámicos y la morfogénesis del área de estudio.

\section{Acceso al área de estudio}

El acceso al área de estudio se hace por la avenida Néstor Gambetta, se llega a la Municipalidad de Ventanilla. Desde este último punto en dirección suroeste hasta una distancia aproximada de 1400 metros (en línea recta) se llega al área de estudio (referencia: playa de Ventanilla).

\section{MATERIAL Y MÉTODOS}

\subsection{Geología}

La geología está conformada por tres componentes litológicos: primero por rocas volcánicas, segundo por material sedimentario, ambos de la cuenca de Lima de la etapa geosinclinal durante la etapa de formación de la Cordillera de los Andes. En tercer lugar, el material superficial del Cuaternario resultado de los procesos de erosión y sedimentación sobre todo marina y eólica. El primero es resultado de derramamientos lávicos y de piroclastos derivados de la actividad volcánica en el sector costanero aledaño al borde occidental andino durante la etapa del geosinclinal andino. El segundo aspecto litológico, tiene edades que van desde el Jurásico hasta el Cretácico superior y se refieren a detritos constituidos en ciclos sedimentarios. En conjunción ambos componentes litológicos configuran una secuencia volcano-sedimentario, que es una de las principales características del sistema plegado de la cordillera de los Andes. El tercer componente litológico es el material sedimentario superficial que es el más joven porque corresponden al 
Cuaternario. Éste último es el resultado de los procesos de erosión y sedimentación marina, eólica y aluvial normalmente en los últimos 10,000 años (reciente).

\subsubsection{Litología}

La litología del área de estudio está señalada en la carta geológica Chancay (24-i) a escala 1: 100 000 del INGEMMET y está conformada por las siguientes unidades:

a. Formación Cerro Blanco. Litológicamente está compuesto por una secuencia sedimentaria volcánica de aproximadamente 180 metros de espesor, predominando los sedimentos en la base y los volcánicos en la cima de la serie. Esta unidad pertenece al Cretáceo inferior. En el área de estudio afloran las rocas volcánicas resultado de derrames andesíticosafaniticos que se presentan en horizontes gruesos. Esta litología se encuentra en los acantilados y colinas en el lugar conocido como Cerro El Perro, localizado al sur de la playa Ventanilla (INGEMMET, 1992, p. 22).

b. Depósitos marinos pleistocénicos. Esta unidad comprende sedimentos (arenas, clastos y cantos aplanados) productos de la abrasión marina. Estos depósitos afloran en el cordón litoral.

Cabe agregar, que estos depósitos del Pleistocénico (1 a 2 millones de años) están cubiertos por materiales superficiales del Holoceno o reciente (últimos 10,000 años) normalmente localizados en la planicie arenosa.

\subsection{Geomorfología}

La Geomorfología es la disciplina geológica-geográfica que tiene por objeto el estudio de las formas del relieve o geoformas, explicando su morfogénesis (origen), desarrollo a escala geológica y su dinámica actual. Teniendo en cuenta ese concepto se ha procedido a estudiar la geomorfología del área de estudio primero señalando las unidades geomorfológicas a una escala 1: 100000 y segundo elaborando un mapa geomorfológico a escala grande 1: 10000.

\subsubsection{Unidades geomorfológicas}

La geomorfología del área de estudio está conformada por las siguientes grandes unidades considerando criterios topográficos, litológicos y morfogéneticos:

a. Acantilados. Los acantilados tienen un origen endógeno derivado de la actividad volcánica en el cretáceo. Son masas de rocas con laderas escarpadas (verticales) en promedio con 50 metros de altura, muy fracturados y con algunas fallas. Son geoformas que contienen abundantes microformas como las cavernas, talud de derrubios, alveolos, etc.

b. Marismas. Es el resultado de los procesos de litoral, es decir del contacto entre las grandes masas de agua del mar (oleajes, tsunamis, mareas) con la erosión y sedimentación continental (acción erosiva del viento). Esto origina una gran zona de sedimentación sobre todo en las planicies que se encuentran a nivel del mar. Resultado de la mencionada conjunción se encuentran geoformas como la planicie intermareal, la planicie arenosa, el cordón litoral, las albuferas. Por otro lado, en el contexto ecológico se forma un ecosistema peculiar conocido como humedales.

\subsubsection{Mapa geomorfológico}

Se ha elaborado un mapa geomorfológico a escala 1: 5000 considerando como base las citadas unidades geomorfológicas, así como la clasificación geomorfológica que ordena las geoformas 
por su origen endógeno o volcánico y por tener una génesis derivada de procesos exógenos (erosión, sedimentación). A continuación, se presenta dos tablas sobre la referida clasificación geomorfológica. La Tabla Nro. 1 señala unidades geomorfológicas que se pueden visualizar en un mapa a escala 1: 5000. En el Anexo Nro. 1 se acompaña un mapa geomorfológico a escala 1: 5 000, del área de estudio, que contribuirá a las investigaciones sobre la geomorfología de los litorales de nuestro país. En la Tabla Nro. 2 menciona el origen del relieve otros de los temas de mayor importancia para la geomorfología.

Tabla Nro. 1. Unidades geomorfológicas, geoformas y dinámica actual

\begin{tabular}{|c|c|c|}
\hline Unidades geomorfológicas & Geoforma & Dinámica actual \\
\hline Acantilado & Acantilado & Abrasión marina, caídas \\
\hline Acantilado & Colina de roca volcánica & Abrasión eólica, caídas \\
\hline Acantilado & Colina con manto de arena & Sedimentación eólica (arenamiento), caídas \\
\hline Acantilado & Caverna & Abrasión marina, oleajes, tsunamis \\
\hline Acantilado & Talud de derrubios & Caídas, arenamiento \\
\hline Acantilado & Campo de ventifact & Abrasión eólica (pulido) \\
\hline Acantilado & Planicie intermareal & Sedimentación marina \\
\hline Acantilado & Relieve residual de roca volcánica & Intrusión marina, oleajes, tsunami \\
\hline Acantilado & Fallas & Desplazamiento de bloques \\
\hline Marisma & Planicie intermareal & Sedimentación marina \\
\hline Marisma & Cordón litoral & Abrasión marina y eólica \\
\hline Marisma & Planicie arenosa & Deflación y sedimentación eólica \\
\hline Marisma & Albufera & Intrusión marina \\
\hline Marisma & Costras de sal & Intrusión marina y haloclastia \\
\hline Marisma & Duna & Sedimentación eólica \\
\hline Marisma & Nebja & Sedimentación eólica y eluviación \\
\hline Marismas & Pantano & Intrusión marina y eluviación \\
\hline
\end{tabular}

Elaboración propia

Tabla Nro. 2. Morfogénesis (origen) de las geoformas

\begin{tabular}{|c|c|c|}
\hline Geoforma & Litología & Morfogénesis \\
\hline Acantilado & Andesita (roca volcánica) & Endógeno \\
\hline Colina de roca volcánica & Andesita (roca volcánica) & Endógeno \\
\hline Colina con manto de arena & Andesita, arenas y bloques & Endógeno \\
\hline Fallas & Andesita & Endógeno \\
\hline Caverna & Andesita y clastos & Exógeno \\
\hline Talud de derrubios & Clastos y arenas & Exógeno \\
\hline Campo de ventifact & Clastos y bloques & Exógeno \\
\hline Planicie intermareal & Arenas y cantos & Exógeno \\
\hline Relieve residual de roca volcánica & Andesita & Exógeno \\
\hline Planicie intermareal & Arenas y cantos & Exógeno \\
\hline Cordón litoral & Arenas y cantos aplanados & Exógeno \\
\hline Planicie arenosa & Arenas y clastos & Exógeno \\
\hline Albufera & Arena y limo & Exógeno \\
\hline Costras de sal & Arena y sal & Exógeno \\
\hline Duna & Arena & Exógeno \\
\hline Nebja & Arena & Exógeno \\
\hline
\end{tabular}




\section{III.RESULTADOS}

\subsection{Geoformas y procesos geodinámicos}

Los procesos geodinámicos comprenden los aspectos geológicos-geomorfológicos que originan modificaciones en la superficie terrestre por acción de esfuerzos tectónicos internos (geodinámica interna) y los procesos exógenos o de erosión (geodinámica externa).

Las geoformas o formas del relieve del área de estudio están afectadas por los procesos geodinámicos de la siguiente manera:

\section{Acantilado}

Escarpe de masa rocosa en la costa de los mares formado como resultado de la abrasión.

Procesos geodinámicos: Los acantilados del área de estudio son activos porque se vienen retrocediendo debido a la erosión o abrasión marina (oleajes y tsunamis). Asimismo, durante los sismos se producen caídas de rocas.

\section{Fallas y fracturas}

Aunque son formas de más de 10 metros de longitud, tiene una elevada importancia desde el punto de vista tectónico. En los acantilados se han observado algunas fallas lo que evidencian esfuerzos tectónicos. Las fracturas son las más evidentes en los acantilados y en las colinas. En los acantilados tienen una dirección vertical y subhorizontal. Esta disposición de las fracturas ha favorecido la erosión intensa de algunos acantilados encontrándose a pocos metros de distancia relieves residuales de roca volcánica.

\section{Colinas de roca volcánica}

Comprende elevaciones con laderas poco inclinadas con alturas entre 100 a 150 metros.

Procesos geodinámicos: Originados por la actividad volcánica en el Cretáceo inferior, posteriormente fueron disectados por la erosión hídrica en forma de cárcavas.

\section{Colinas con mantos de arena}

Geoforma de acumulación de arena por acción del viento sobrepuesta a las laderas de la colina.

Procesos geodinámicos: Las laderas de las colinas están muy fracturadas y erosionado esto ha facilitado la sedimentación sumada a la humedad.

\section{Relieve residual de roca volcánica}

Se trata los restos de la parte central de antiguas colinas o acantilados que fueron erosionados por la abrasión marina.

Procesos geodinámicos: Esas masas rocosas residuales están siendo erosionadas por el viento y en su base están alteradas por la intrusión marina y la haloclastia, por esa razón están rodeados de costras salinas.

\section{Caverna}

Oquedad en la masa rocosa de los acantilados con un acceso horizontal, de 1 a 20 metros de altura) originado por la abrasión marina (oleajes o tsunamis). Las cavernas del área de estudio tienen 
conductos de entrada y salida. En el interior de la caverna se puede observar el fracturamiento interno de la masa rocosa.

Procesos geodinámicos: El suelo del interior de la caverna tienen capas de fango resaltado de las inundaciones durante las mareas. Asimismo, por las líneas de fractura de la masa rocosa del acantilado se infiltra el agua condensada por la humedad e ingresa al interior de la caverna.

\section{Talud de derrubios y cono de derrubios}

Material superficial (clastos, arenas y bloques) que por procesos coluviales se han deslizado y caído al pie de los acantilados. Si estos materiales siguen un camino de erosión forma un cono de derrubios y de lo contrario se desarrollan los taludes de derrubios.

Procesos geodinámicos: Debido a los procesos de erosión eólica estas geoformas se alteran y luego son alimentados por las caídas durante los sismos.

\section{Campos de ventifact}

Compuestos por clastos o derrubios, dispersados por los campos de arena, que han sido pulidos por la acción abrasiva del viento (facetado), se localizan contiguos a los acantilados.

Procesos geodinámicos: Estos clastos se originan por las caídas y arrastrados por oleajes anómalos y luego erosionados por el viento.

\section{Planicie intermareal}

Es un espacio de topografía plana permanentemente inundada por las altas mareas y rellenada con arenas durante los oleajes.

Procesos geodinámicos: Las mareas y los oleajes van removilizando los sedimentos. Asimismo, está expuesto a la erosión y sedimentación del viento.

\section{Cordón litoral}

Es un banco submarino que actualmente aflora paralelo a la línea de alta marea. Esa geoforma tiene una altura entre 5 a 10 metros de altura.

Procesos geodinámicos: El cordón litoral viendo siendo erosionado por el viento. Cabe agregar, que la población ha cortado la altura original de esa geoforma para facilitar su acceso a la playa (Planicie intermareal).

\section{Albufera}

Es una laguna separada del mar por un cordón litoral. Las albuferas del área de estudio se originaron de la siguiente manera: Primero por deflación eólica (el viento excava el suelo arenoso al impactar cargado de partículas) originando depresiones y dejando el terreno debajo del mar. Segundo por intrusión marina se inundan las depresiones originándose las albuferas.

Procesos geodinámicos: las albuferas tienen un régimen hídrico resultado de los procesos de litoral. Es decir, por un lado, hay una alimentación marina por intrusión favorecido por el material permeable del suelo (arenas). De otra parte, la evaporación debido a las altas temperaturas de estos espacios áridos o desérticos (escases de lluvias). Estos procesos de litoral generan un ecosistema denominado «humedales» desde el punto de vista biológico o ecológico. 


\section{Planicie arenosa}

Superficie de topografía plana consistente en depósitos eólicos y marinos. Es una planicie que se encuentra a nivel del mar.

Procesos geodinámicos: Se encuentran expuestos a la intrusión marina sobre todo en los terrenos deprimidos topográficamente.

\section{Costras de sal}

Comprenden pequeñas áreas con afloramientos de sal sobre las planicies arenosas donde la evaporación es alta. Es el resultado de los procesos de meteorización salina o haloclastia.

\section{Duna}

Acumulaciones de arena debido a la sedimentación del viento en los litorales marinos. Estas geoformas tienen una ladera muy inclinada y otra con un declive más suave.

Procesos geodinámicos: La acumulación o sedimentación eólica es intensa sobre todo en zonas aledañas a los acantilados y el cordón litoral.

\section{Nebja}

El Nebja es una duna que por la humedad ha sido intensamente meteorizado generándose procesos eluviales y luego colonizado por la vegetación.

Procesos geodinámicos: Los Nebjas también sufren una intrusión marina y es probable que sean dunas antiguas con un centro muy compacto.

\section{Pantano}

Terreno arenoso continental con humedad y agua producto de la intrusión marina altamente meteorizado (eluviación) que genera una vegetación hidrófila.

Procesos geodinámicos: Estas geoformas contiene material limoso y materia orgánica resultado de un inicial proceso edáfico.

En los Anexo Nro. 2 y 3 se muestra las fotografías de cada una de las geoformas del área de estudio.

\subsection{Microformas}

Las microformas tienen longitudes que van desde pocos centímetros hasta 2 metros. Por esa razón, normalmente no se grafican en los mapas geomorfológicos. En el Anexo Nro. 4, se presenta las fotos de las microformas. Para el caso estudiado se pueden citar las siguientes formas del relieve.

\section{Alveolos o picaduras de abrasión}

Se trata de hoyuelos de pocos centímetros de diámetro incluso milímetros resultados de perforaciones sobre la masa rocosa que realiza frontalmente el viento cargado de partículas.

\section{Acanaladuras}

Se trata de una serie de hendiduras o microcanales que siguen la dirección del viento. También es originado por una erosión eólica. 


\section{Ripples eólicos}

Se trata de pequeñas ondulaciones sobre los campos de arenas originadas por la sedimentación del viento. Es consecuencia de la caída de los granos de arena formando micro montículos favorecidos por la humedad.

\section{Derrubios sobre las colinas con mantos de arena}

Son bloques entre 30 a 50 centímetros de diámetro que están dispersados por la ladera arenosa de las colinas debido a las caídas durante los sismos o por perdida de inercia de los bloques que se desprenden de la masa rocosa por procesos gravitatorios.

\section{DISCUSIÓN DE RESULTADOS}

\subsection{Morfogénesis}

La morfogénesis se encarga de explicar el origen del relieve, para el caso por un lado tiene relación con la actividad volcánica de la cuenca de Lima en el cretáceo inferior durante la fase geosinclinal de la cordillera de los Andes. Esa actividad volcánica se refleja actualmente en las geoformas de acantilados y colinas de rocas volcánicas, en tanto las fracturas y fallas es consecuencia de esfuerzos tectónicos en la etapa de levantamiento de la cordillera de los Andes.

Esos aspectos geológicos-geomorfológicos condicionaron los procesos de erosión marina, sobre todo durante los oleajes y tsunamis, que impactaron sobre los acantilados probablemente en el cuaternario pleistocénico, causando su retroceso y la formación de cavernas. En el cuaternario reciente el viento fue y sigue siendo un agente importante de erosión reflejado en las geoformas de dunas, planicie arenosa, alveolos. campos de ventifact y albuferas. La intrusión marina es otro proceso de suma importancia porque es otro factor que participa en la generación de la geoforma de pantanos (ecosistema de Humedales).

Asimismo, la planicie arenosa contiene otras geoformas típicas de las zonas de marismas como por ejemplo el cordón litoral, las albuferas y las costras salinas.

\subsection{Dinámica actual}

Una de las aplicaciones de la geomorfología de mayor importancia actualmente es el estudio de la geodinámica externa con fines de planificación física (propuestas de usos de suelo) o de zonificación de peligros en el marco de la gestión de riesgos de desastres, considerando una escala de tiempo similar al desarrollo de la sociedad.

En este trabajo se está señalando la dinámica actual (ver Tabla Nro. 1), es decir los procesos de erosión activos que tienen diferentes frecuencias de ocurrencia, por ejemplo, los tsunamis. La probabilidad de que una zona de marismas sea impactada por tsunamis (olas de más de 20 metros de altura) es alta porque son terrenos con topografía plana, sin embargo, condicionado con la ocurrencia de sismos que es un factor endógeno. Las caídas de bloques y partículas también están relacionadas con los sismos los que podrían impactar algunos caminos aledaños a los acantilados. 
Por el lado, ecológico las intrusiones marinas son permanentes y pueden dar sostenibilidad a los ecosistemas de humedales sin embargo se ha observado algunas alteraciones antrópicas en las zonas de albuferas y acantilados.

\section{CONCLUSIONES}

1. La notoriedad de los acantilados y su evolución es resultado de procesos volcánicos, tectónicos y los procesos de erosión ocurridos en el cuaternario. Las cavernas y los relieves residuales indican la intensidad de la erosión (abrasión marina) y su capacidad para nivelar las referidas geoformas.

2. La topografía plana y arenosa de la zona de marismas y la intrusión marina sobre esos terrenos delimita una unidad de litoral denominada en nuestro país como franja de litoral. El litoral es una zona de contacto entre el mar y el continente. En este espacio ocurren procesos de litoral (erosión y sedimentación) que originan el ecosistema de humedales o pantanos. Por esa razón, los estudios de litorales también tienen carácter ambiental o ecológico.

3. Los términos costa y litoral se suelen emplear casi como sinónimos, sin embargo son diferentes. Costa tiene un contexto más geológico o litológico, por ejemplo, la formación geológica Cerro Blanco, es volcánico y sedimentario que se extiende desde el continente hasta la parte sumergida (mar). Esas masas rocosas o de basamento es un ejemplo de costa. Mientras que litoral como se señaló anteriormente comprende un contexto más ecológico y ambiental como producto del contacto entre grandes masas de agua (mar) y el relieve continental. Es decir, el ecosistema resultado de los procesos de meteorización y erosión. Por ejemplo, los humedales o pantanos es un espacio litoral.

4. Las acciones de erosión y sedimentación del viento son relevantes porque en el área de estudio prácticamente no hay lluvias y la geoforma de planicie arenosa es muy extensa con escasa rugosidad lo que genera que las velocidades del viento sean altas. Las geoformas de dunas y alveolos son indicadores de los citados procesos.

5. En el plano de los peligros de origen natural teniendo en cuenta que el Perú forma parte del Cinturón de Fuego de Pacifico, es un país símico, situación que se relaciona con la posibilidad de ocurrencia de tsunamis. La topografía plana y a nivel del mar de la zona de marisma lo convierte en un espacio de peligro muy alto a ser impactado por los tsunamis.

6. Para definir líneas de probables impactos de un eventual tsunami se requiere hacer un levantamiento con cotas cada metro. Podría señalarse líneas de cota cada 5 metros para indicar niveles de peligros por el impacto de los tsunamis. Luego, se tendría que realizar simulaciones con olas de 10, 20 y hasta 30 metros de altura. El «golpe» de esas enormes olas son las acciones de origen natural que podrían afectar a los asentamientos humanos que se localizan aledaños al área de estudio. Es decir, el peligro de origen natural por tsunamis, en primer lugar, es el impacto de las mencionadas olas, con alturas mayores a 10 metros, que podrían impactar en las viviendas. En segundo lugar, estaría ocurriendo las inundaciones luego de disiparse el aludido tsunami. Posteriormente, la evaporación dejaría potentes capas de arenas que fosilizarían el suelo primigenio. 


\section{Anexos}

Anexo Nro. 1. Mapa Geomorfológico Sector Acantilados y Marismas - Ventanilla

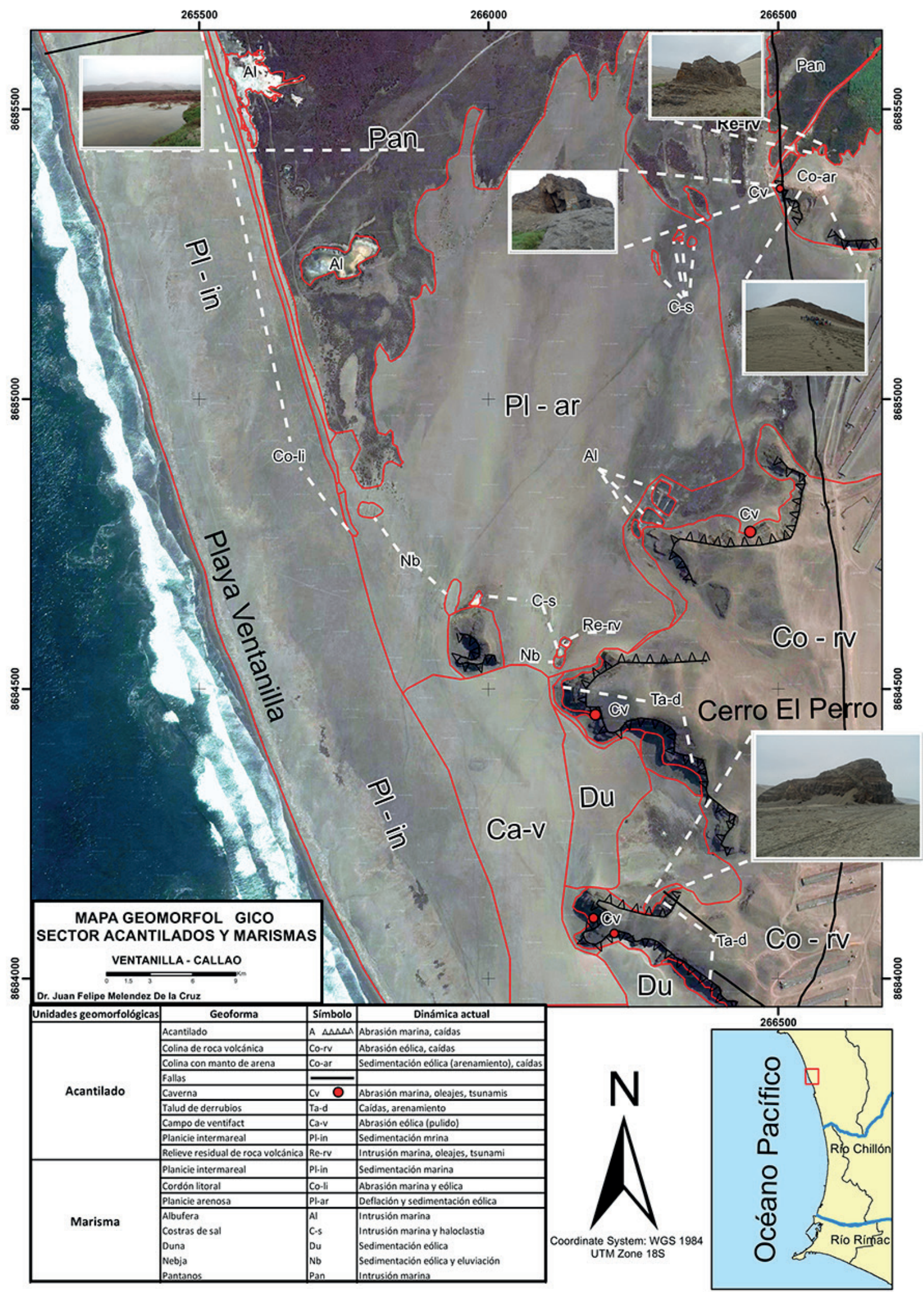


Anexo Nro. 2. Fotos geoformas del sector Acantilados
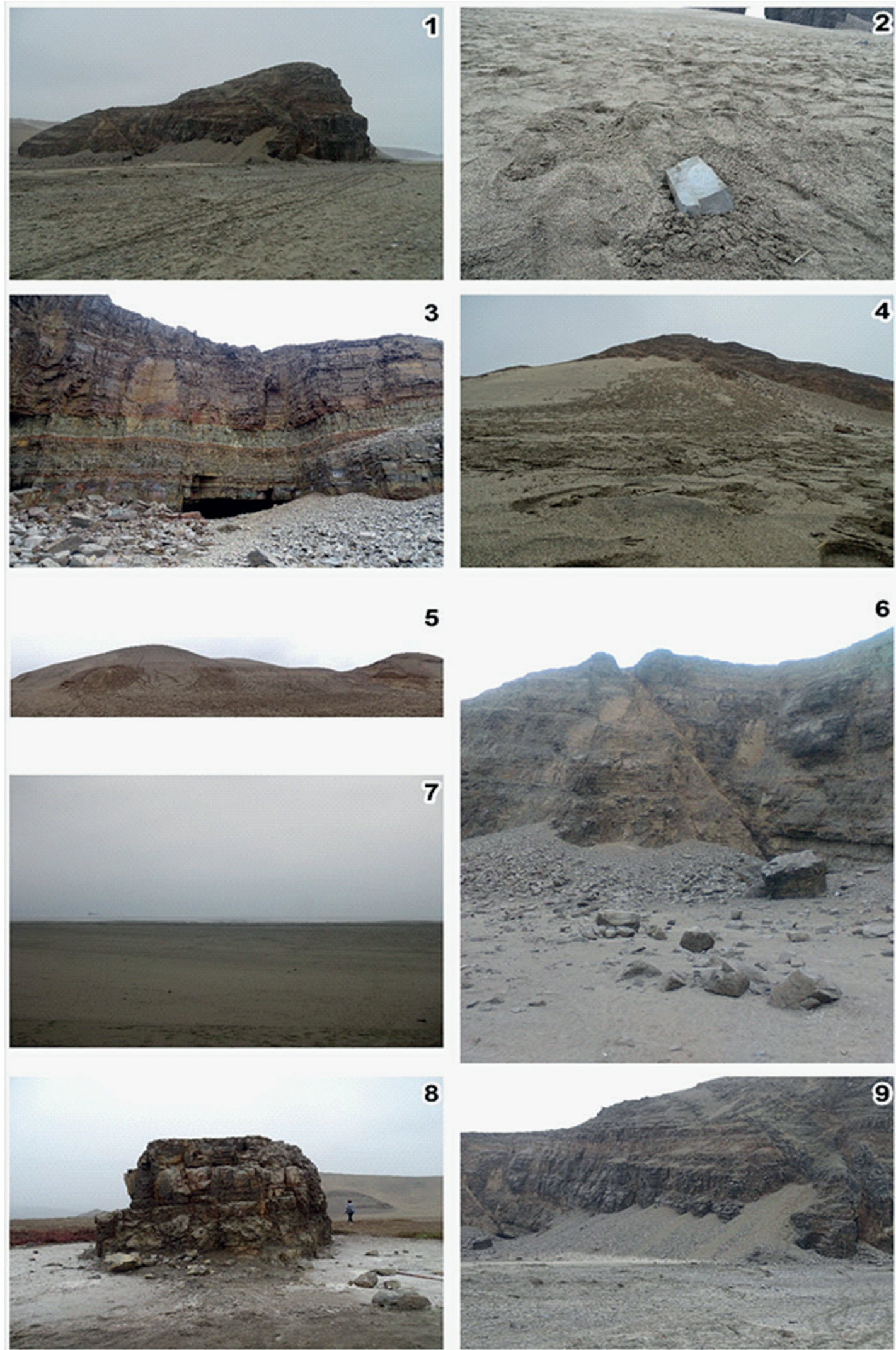

1. Acantilado (A). 2. Campo de ventifact (Ca-v). 3. Caverna (Cv). 4. Colina con manto de arena (Co-ar). 5. Colina de roca volcánica (Co-rv). 6. Falla. 7. Planicie intermareal (PI-in). 8. Relieve residual de roca volcánica (Re-rv)

9. Talud de derrubios (Ta-d) 
Anexo Nro. 3. Fotos geoformas del sector Marismas
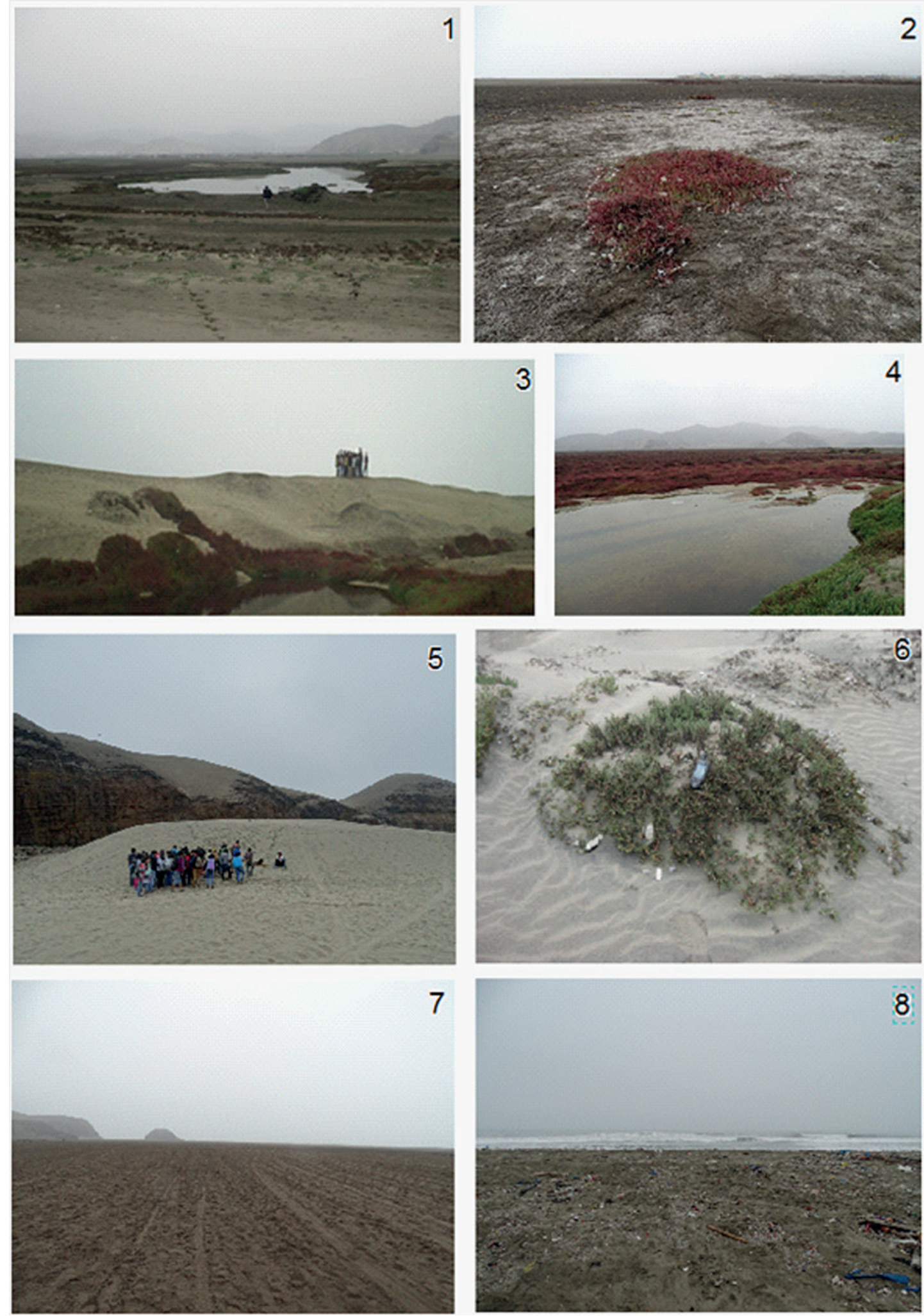

1. Albufera (Al). 2. Costras de sal (C-s). 3. Cordón litoral (Co-li). 4. Pantano (Pan). 5. Duna (Du). 6. Nebja (Nb). 7. Planicie arenosa (PI-ar). 8. Planicie intermareal (PI-in) 
Anexo Nro. 4. Fotos de microformas
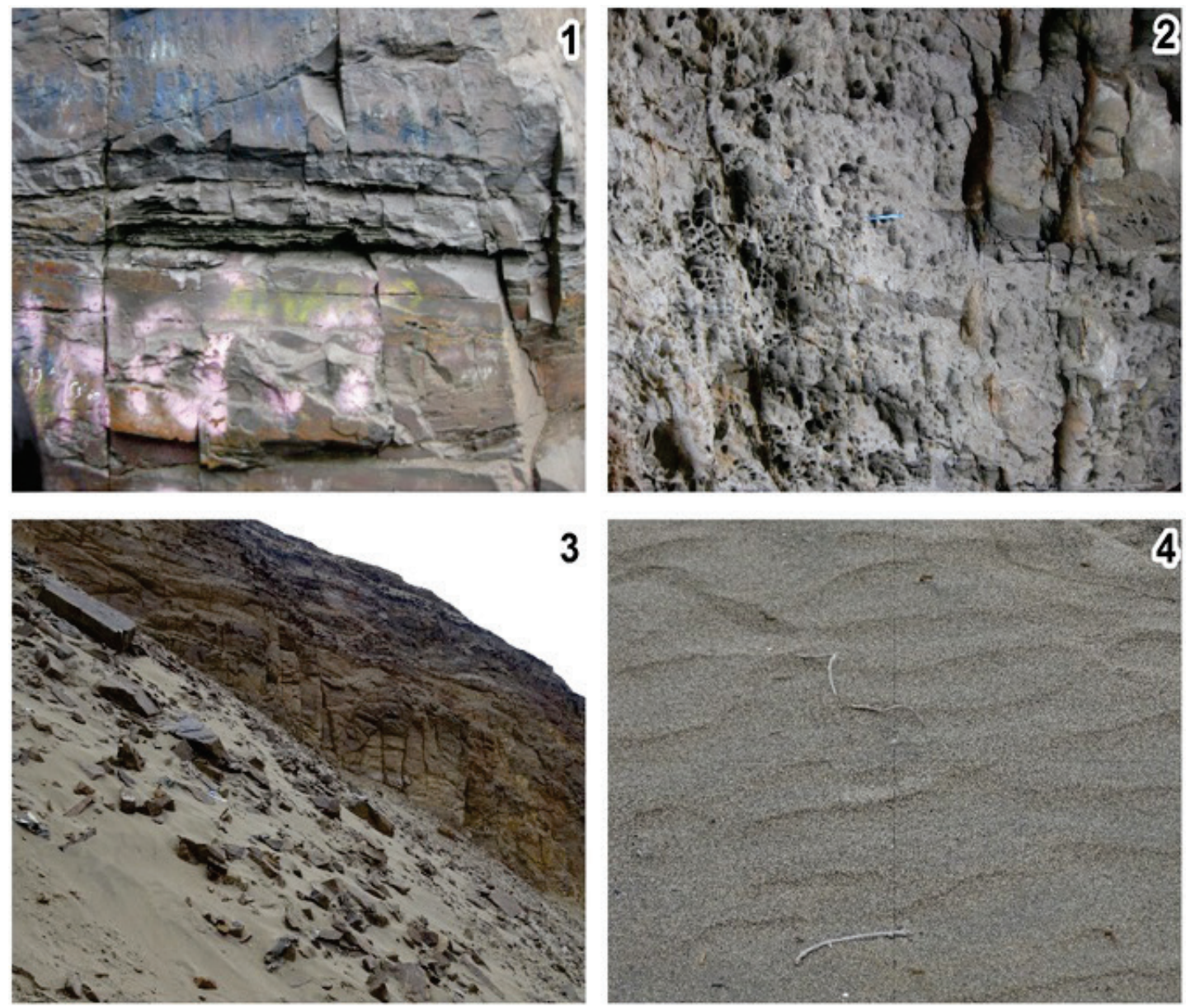

1. Acanaladuras. 2. Alveolos. 3. Derrumbios sobre colina con manto de derrubios. 4. Ripples eólicos

\section{Bibliografía}

Carenas, M. y Giner, J. (2014). Geología. Madrid: Lavel Industria Gráfica.

Centro Nacional de Estimación, Prevención y Reducción del Riesgo de Desastres (CENEPRED) (2015). Manual para la evaluación de riesgos originados por Fenómenos Naturales. Lima.

Dávila, J. (2011). Diccionario geológico. Lima.

De Pedraza, J. (1996). Geomorfología - Principios, métodos y aplicaciones. Madrid: Editorial Rueda.

Instituto Geológico Minero y Metalúrgico. (1995). Geología del Perú. Boletín, 55.

Instituto Geológico minero y Metalúrgico. (1992). Geología de los cuadrángulos de Lima, Lurín, Chancay y Chosica. Boletín, 43.

Lugo, J. (1989). Diccionario geomorfológico. México: Universidad Autónoma de México. 
